Check for updates

For numbered affiliations see end of article.

Correspondence to: $\mathrm{K}$ Walker katie_walker01@yahoo.com.au (ORCID 0000-0002-5313-5852) Additional material is published online only. To view please visit the journal online.

Cite this as: BMJ 2019;364:1121 http://dx.doi.org/10.1136/bmj.l121

Accepted: 7 January 2019

\title{
Impact of scribes on emergency medicine doctors' productivity and patient throughput: multicentre randomised trial
}

\author{
Katherine Walker, ${ }^{12}$ Michael Ben-Meir, ${ }^{12}$ William Dunlop, ${ }^{13}$ Rachel Rosler, ${ }^{4}$ Adam West, ${ }^{4}$ \\ Gabrielle O'Connor, ${ }^{5}$ Thomas Chan, ${ }^{56}$ Diana Badcock, ${ }^{7}$ Mark Putland, ${ }^{478}$ Kim Hansen, ${ }^{9} 10$ \\ Carmel Crock, ${ }^{11}$ Danny Liew, ${ }^{12}$ David Taylor, ${ }^{613}$ Margaret Staples ${ }^{214}$
}

\section{ABSTRACT}

OBJECTIVES

To evaluate the changes in productivity when scribes were used by emergency physicians in emergency departments in Australia and assess the effect of scribes on throughput.

\section{DESIGN}

Randomised, multicentre clinical trial.

SETTING

Five emergency departments in Victoria used Australian trained scribes during their respective trial periods. Sites were broadly representative of Australian emergency departments: public (urban, tertiary, regional referral, paediatric) and private, not for profit.

\section{PARTICIPANTS}

88 physicians who were permanent, salaried employees working more than one shift a week and were either emergency consultants or senior registrars in their final year of training; 12 scribes trained at one site and rotated to each study site.

\section{INTERVENTIONS}

Physicians worked their routine shifts and were randomly allocated a scribe for the duration of their shift. Each site required a minimum of 100 scribed and non-scribed shifts, from November 2015 to January 2018.

\section{MAIN OUTCOME MEASURES}

Physicians' productivity (total patients, primary patients); patient throughput (door-to-doctor time, length of stay); physicians' productivity in emergency department regions. Self reported harms of scribes were analysed, and a cost-benefit analysis was done.

\section{WHAT IS ALREADY KNOWN ON THIS TOPIC}

Scribes in emergency medicine have been reported to increase productivity in some studies and provide no gains in others

Scribes are well tolerated by patients, and most physicians find working with scribes beneficial

No multicentre randomised studies have been done, and patient safety incidents (adverse events or near misses) associated with scribes have not been evaluated

\section{WHAT THIS STUDY ADDS}

Emergency physicians who used scribes increased their productivity by 0.18 patients per hour per doctor (15.9\%) while emergency department length of stay decreased by 19 minutes per patient

A patient safety incident (adverse event or near miss) involving a scribe was reported in 1 in 300 consultations, mainly involving incorrect patient identification and investigation ordering

Financial cost-benefit analysis supported a scribe programme

\section{RESULTS}

Data were collected from 589 scribed shifts $(5098$ patients) and 3296 non-scribed shifts (23838 patients). Scribes increased physicians' productivity from 1.13 (95\% confidence interval 1.11 to 1.17 ) to 1.31 (1.25 to 1.38 ) patients per hour per doctor, representing a $15.9 \%$ gain. Primary consultations increased from 0.83 (0.81 to 0.85 ) to 1.04 (0.98 to 1.11) patients per hour per doctor, representing a $25.6 \%$ gain. No change was seen in door-to-doctor time. Median length of stay reduced from 192 (interquartile range 108-311) minutes to 173 (96208) minutes, representing a 19 minute reduction $(P<0.001)$. The greatest gains were achieved by placing scribes with senior doctors at triage, the least by using them in sub-acute/fast track regions. No significant harm involving scribes was reported. The cost-benefit analysis based on productivity and throughput gains showed a favourable financial position with use of scribes.

\section{CONCLUSIONS}

Scribes improved emergency physicians' productivity, particularly during primary consultations, and decreased patients' length of stay. Further work should evaluate the role of the scribe in countries with health systems similar to Australia's.

TRIAL REGISTRATION ACTRN12615000607572 (pilot site); ACTRN12616000618459.

\section{Introduction}

A medical scribe helps the physician by doing clerical tasks. The scribe stands with the physician at patients' bedsides, documenting consultations, arranging tests and appointments, completing electronic medical record tasks, finding information and people, booking beds, printing discharge paperwork, and doing clerical tasks (box 1). ${ }^{1}$ They do this via a computer-on-wheels connected to the hospital's electronic medical record system. The aim of the role is for scribes to do clerical tasks otherwise done by the physician, enabling the physician to manage more patients in the same amount of time.

Patients tolerate the presence of scribes well, ${ }^{2-4}$ and less than $1 \%$ of consultations are inappropriate for scribes. ${ }^{4}$ Most doctors working with scribes support or strongly support their use, ${ }^{25-7}$ with $15 \%$ preferring not to work with scribes. ${ }^{6}$ Documentation done by scribes seems to be adequate, ${ }^{8}$ although the tools used for evaluating quality have been questioned. ${ }^{9}$ If no major problems regarding quality or risk have been identified 
Box 1: Tasks done by scribes

- Electronic physician allocation

- Locating nurses' notes

- In-room documentation of:

- History

- Physical examination

- Medical plan

- Investigation results/interpretations

- Progress in emergency department

- Diagnosis

- Disposition plan

- Safety net information

- Information retrieval:

- Primary care letters

- Clinic/specialist letters

- Previous hospital records

- Previous investigations

- Facilitation of investigations:

- Adding clerical details to requests

- Faxing investigation requests

- Calling in radiology staff

- Coordinating with porters

- Confirming bookings and times

- Communicating plans to nurses

- Troubleshooting investigation delays

- Post-initial consultation tasks:

- Booking beds

- Conveying written requests to nurses/allied health staff

- Paging registrars/residents

- Locating specialists

- Obtaining specialists on the telephone

- Documenting specialist phone opinions

- Documenting specialist consultations

- Time based data entry

- Mandatory registry data entry

- Discharge preparation:

- Printing sick certificates

- Making review appointments

- Printing referral letters

- Making outpatient test appointments

- Printing advice sheets

in association with use of scribes, the decision about scribe programmes will rest largely on information about their cost effectiveness.

Limited economic research on scribes has been conducted in emergency medicine in the US. ${ }^{1} 7$ 10-14 Some pilot economic data are available from emergency departments showing that allocation of scribes to some, but not all, physicians is likely to prove economically viable in Australia. ${ }^{15-18}$ Studies from other specialties support the scribe role. ${ }^{19-23}$ Evaluations have shown increased medical productivity, 1121516202425 but not necessarily faster emergency department throughput, for which the literature is in equipoise. 171011131516

At the time of planning of this study, no multicentre randomised studies on the effect of scribes on emergency physicians' productivity had been done. ${ }^{24}$ The presence of scribes in the US has risen to $25 \%$ of emergency physicians' shifts, with limited evidence supporting their efficacy. Interest exists in scribe programmes in Canada, Australia, New Zealand, and the UK, and almost all health services struggle with demands not matching available resources. The scribe's role needs to be evaluated in settings that represent some of the breadth and variety of emergency departments before widespread implementation of scribe programmes at considerable opportunity cost. ${ }^{17}$ Greater understanding of the effect of scribes on physicians' productivity will help to inform decisions about whether to start scribe programmes.

We evaluated the productivity of emergency physicians working with and without scribes in Australian emergency departments. We also evaluated emergency department throughput and the effect of scribes in each region of the emergency departments and describe patient safety incidents associated with the presence of scribes.

\section{Methods}

\section{Study design}

We did a prospective, multicentre, non-blinded, randomised clinical trial between November 2015 and January 2018. Emergency physicians who provided written informed consent had a scribe randomly allocated to their routine shifts, and we compared their productivity between contemporaneous scribed and non-scribed shifts.

\section{Participants \\ Sites}

The study took place at five emergency departments in the state of Victoria, Australia (Cabrini (pilot site), Dandenong, Austin, Bendigo, and Monash Paediatrics). Each site participated by employing competent scribes who had been trained at Cabrini. ${ }^{17} 18$ We purposely selected these sites to represent typical Australian emergency departments. The delineations of the sites enrolled were public/Medicare: metropolitan, tertiary, paediatric, regional referral, and private tertiary (not for profit). The roles of the physicians differed at each site and are described in table 1 . Some sites use a senior doctor for a medical triage role. This involves identifying potential emergencies and starting diagnostic investigations and treatment for patients before they are seen by another physician in the main emergency department. ${ }^{26}$ This triage physician can also discharge patients if they do not need ongoing care. Medical records were either an electronic medical record (Dandenong, Austin, Monash Paediatrics) or a digital medical record with a combination of electronic and paper systems (Cabrini, Bendigo).

\section{Physicians}

Emergency physicians were eligible for enrolment if they were consultants and permanently employed for at least one shift a week. Eligibility for participation was changed at Bendigo and Monash after the start 


\begin{tabular}{|c|c|c|c|c|c|}
\hline Hospital & Cabrini & Dandenong & Austin & Bendigo & Monash \\
\hline Funding & Private* & Publict & Publict & Publict & Publict \\
\hline \multicolumn{6}{|l|}{ Emergency department } \\
\hline Description & Tertiary & Metropolitan & Tertiary & Regional referral & Paediatrics \\
\hline No of cubicles & 21 & 30 & 50 & 30 & 22 \\
\hline Mean patient age, years & 57 & 42 & 45 & 42 & 6 \\
\hline No (\%) admissions & $11380(56)$ & $8983(21)$ & $12139(24)$ & $3990(20)$ & $1992(11)$ \\
\hline No (\%) adults $\geq 65$ years & $10046(49)$ & $9567(21)$ & $15890(31)$ & $5102(25)$ & 0 \\
\hline No (\%) paediatrics $<18$ years & $2892(14)$ & $7911(18)$ & $11200(22)$ & $4594(23)$ & $17877(97)$ \\
\hline Electronic or digital medical record & PAS‡ (DMR) & Symphonył (EMR) & Cerner‡ (EMR) & Vitroł (DMR) & Symphony (EMR) \\
\hline Paediatric unit & No & No & Yes & No & Yes \\
\hline $\begin{array}{l}\text { Emergency department observation } \\
\text { unit }\end{array}$ & No & Yes & Yes & Yes & Yes \\
\hline Direct patient care & Yes & Yes & Yes & Yes & Yes \\
\hline Supervision§ & Minimal & Yes & Yes & Yes & Yes \\
\hline \multicolumn{6}{|c|}{$\begin{array}{l}\text { DMR=digital medical record; EMR=electronic medical record. } \\
\text { *Private, not for profit, Catholic (income from a combination of government, private insurers, and patient funds). } \\
\text { tPublic funding mainly from state government. } \\
\text { †Patient Administrative Systems (v10.10, iSOFT, Sydney, Australia); Symphony (V2.37.1.23, Emis Health, Leeds, UK); Cerner (V3, Cerner, North Kansas, } \\
\text { USA); Vitro (V2.6.16, Sláinte Healthcare, Dublin, Ireland). } \\
\text { §Supervision of junior medical staff teams and overseeing department flow and activity. }\end{array}$} \\
\hline
\end{tabular}

of the study because the pool of consultants was too small to allow timely completion of the study. Senior emergency medicine physician trainees (in the final two years of fellowship training) were eligible to participate at these sites as well as consultants, provided that the trainees met all other eligibility criteria. All physicians were salaried employees who were paid per hour, not per patient. Participation was voluntary, and all eligible physicians were invited to participate by email before implementation of scribes. The site coordinator at each site facilitated this process (KW, RR, GOC, MP, AW). Physicians were offered 90 minutes of training online and a 90 minute dial-in telephone training session before receiving scribes. Very few physicians took up the offer of training.

\section{Scribes}

All scribes were trained until competent at Cabrini before the study and gave consent for participation. We recruited scribes via advertisement, and training of scribes has been described previously for this cohort. ${ }^{17} 18$ Training was delivered in three sections: pre-clinical training using a commercially available blended course with a textbook and e-learning modules (taking 30-40 hours) ${ }^{27} 28$; two classroom days including emergency department orientation, lectures, and patient simulation and feedback; and finally a clinical apprenticeship with a physician trainer until competent (range 3-16 shifts, competency tested every shift until achieved). Two head scribes were responsible for allocation and management of scribes' shifts. They managed a pool of 12 scribes who were simultaneously employed at all sites and rotated to each site during its active study period.

\section{Patients}

All patients attending the participating emergency departments were eligible for scribe involvement except at the request of the patient or the discretion of the physician (sensitive consultation). The number of patients declining scribes was not recorded. Physicians allocated their name to a patient by using the electronic medical record system. We included patients seen by a physician on a scribe shift in the scribe group, regardless of whether the scribe was present for the consultation. If a physician did not allocate their name to a given patient on the electronic medical record (for example, a junior doctor was the primary physician and the consultant their advisor), we excluded that patient encounter.

\section{Workflow}

Physicians visit patients according to their allocated role for the shift. Senior doctors at triage see patients shortly after nursing triage to start treatment. Other physicians will see patients who have been allocated a treatment space. Patients with a triage category of 1 or 2 are seen almost immediately. The rest are usually seen in order of arrival and according to team or regional streaming. Consultants have discretion to visit patients out of order according to their assessment of their capacity while multitasking with an individual patient load and simultaneously supervising other providers and patient throughput. ${ }^{29}$

When no scribe is present, the usual practice of when physicians document consultations varies. Some physicians document at the bedside (or at triage) during the consultation, others sit or stand at a desktop computer after each consultation, and some document multiple patient encounters later on when they are able. 


\section{Randomisation and allocation}

Physicians' rosters were determined several months in advance, with changes made for sick leave or other reasons. We did not distribute these rosters to scribes. Every two weeks, scribes gave their availability and a head scribe used a computer generated random number to allocate scribes to doctors' shifts. If only one shift was available during a given scribe's availability, randomisation was not possible and no allocation was made. Public holidays and overnight shifts were excluded from both groups to contain the research budget. Dandenong and Austin had dedicated emergency department observation unit shifts at which the site directors thought that scribes would not provide benefit. At these sites, emergency department observation unit shifts were excluded from allocation and analysis. Bendigo has emergency department observation unit shifts that are paired with a sub-acute patient load, and scribes were considered of potential use in this setting. Therefore, emergency department observation unit shifts were eligible for scribe allocation at Bendigo. Cabrini and Monash paediatric emergency departments have no dedicated emergency department observation unit shifts. Allocation was concealed until publication of the scribe roster, which could not be changed once published, except for last minute physician sick leave, when either an alternative participating physician was identified on the same shift or, if no eligible alternate was identified, the scribe was sent home. If a scribe needed sick leave, the scribe's shift was cancelled and we included the physician's shift in the non-scribed group. Blinding to the presence or absence of a scribe during a shift or during data analysis was not possible.

Allocation of patients to a physician was not randomised. In Australian emergency departments, consultants and juniors provide direct patient care and consultants also simultaneously supervise multiple other healthcare providers within the emergency department. Consultants choose patients that they feel they have the capacity to manage at any given time (on the basis of a mix of urgency, wait times, patient complexity, available junior skill mix, and resources), and this capacity to select patients was not altered during this study for either the scribed or non-scribed group.

\section{Intervention}

Scribes accompanied their allocated physician for the whole shift. The scribe used either an in-room computer or a computer-on-wheels to document consultations while the physician assessed the patient. Scribes also did other clerical duties as described in box 1 . Physicians edited and verified scribes' documentation before electronic medical record sign-off.

\section{Outcomes}

The primary outcome was the difference in physicians' productivity between scribed and non-scribed shifts. Secondary outcomes were door-to-doctor times, emergency department length of stay times, regional physicians' productivity, and rates of primary consultations.

We deemed a consultation a primary consultation when the physician was the main physician for the patient (including medical triage consultations in which the patient was immediately discharged without further care from a physician). A secondary consultation was either a medical triage consultation (when the patient is later seen by another physician for a full consultation) or a handover consultation.

We encouraged the scribes and emergency physicians to report patient safety incidents involving the scribes into an anonymous, online, specialty specific incident reporting system (www.emer.org.au). The Emergency Medicine Events Registry (EMER) was established by the Australasian College for Emergency Medicine (ACEM) and the Australian Patient Safety Foundation (APSF). Incidents were collated, categorised, and analysed by an expert panel including emergency physicians. They used an error classification system specific to emergency medicine. ${ }^{30}$

We did a post hoc, exploratory analysis of the costbenefits of a scribe programme from the perspective of one hospital, using this study and previously published data from this scribe programme (appendix 1). We made assumptions as required and reported them. We determined the cost of the scribe by incorporating training costs, the number of shifts scribes will work in their careers, and scribes' wages. We calculated the costs of productivity gains by comparing physician costs of productivity gains with scribe costs for the same gains. We determined savings generated by increased throughput by using a calculated cost per staffed cubicle perw minute. We calculated total costs and savings (overall financial positions) with the varying scenarios of training paid for by the hospital or the scribe.

Shift data came from rostering databases, which were confirmed for accuracy each week. We excluded from analysis any unrecorded and unpaid overtime hours of physicians for the purpose of writing notes. Patient data, including physician allocations, came from each site's electronic medical record database.

\section{Statistical analysis}

Previous work at Cabrini calculated a mean throughput of 0.83 patients per hour per doctor with a standard deviation of $0.3 .^{16}$ We sought a $15 \%$ productivity gain from the scribe to create a break-even business case for scribes (an increase from 0.83 to 0.95 consultations per doctor per hour), based on estimated hourly salaries (including 25\% "on-costs" to fund pension contributions, leave pay, and insurance) of physicians (US\$129.81; £101; €113) and scribes (US\$15.91). ${ }^{17}$ Using a two sided, 5\% significance level, we needed 1000 shifts in total (100 scribed and 100 non-scribed from each of the five sites) to achieve $80 \%$ power to detect this difference. We calculated total consultations per hour per doctor by using the sum of primary and 
secondary patient encounters for each doctor, divided by the hours worked each shift.

We analysed characteristics of the patient populations and shift level data by using the KruskallWallis equality-of-populations rank test (age, door-todoctor time and length of stay, physicians' productivity) and $\chi^{2}$ tests for categorical variables. Given a positive skew in patients per hour, we used a Kruskall-Wallis test to compare primary outcomes between scribed and non-scribed groups. We determined the effect of the scribe by using linear or logistic regression, as appropriate, with the presence of a scribe as a predictor. We used Stata version 14.2 for calculations.

\section{Patient and public involvement}

Previous work showed that patients are ambivalent about the presence of a scribe. ${ }^{4}$ No patients were involved in setting the research question or the outcome measures, nor were they involved in developing plans for or implementation of the study. No patients were asked to advise on interpretation or writing up of results.

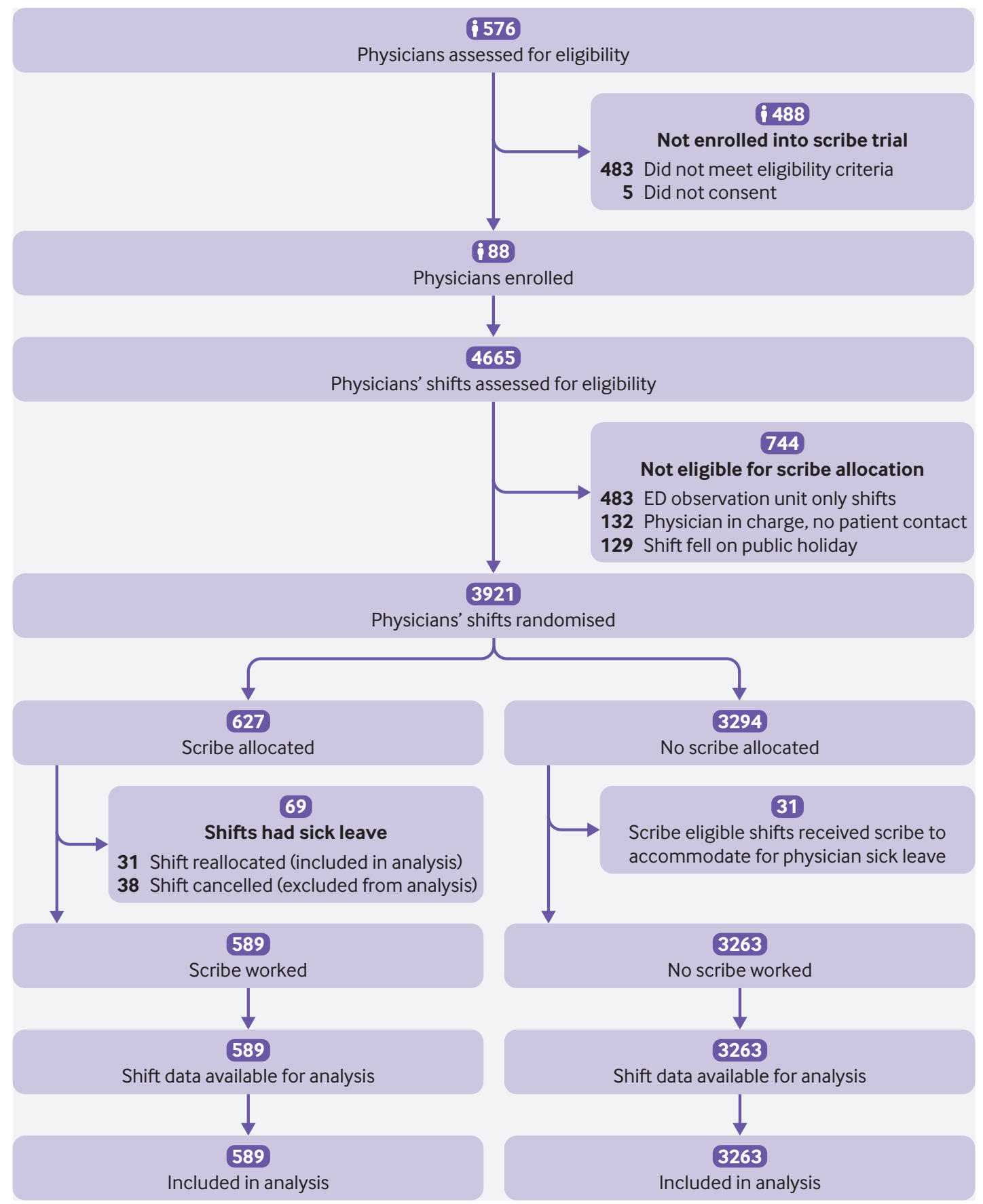

Fig 1 | Flow chart of study. Two physicians withdrew mid-study as they did not find scribes useful; they consented to their completed shifts being included in the analysis, and these shifts are accounted for in the flow chart 


\begin{tabular}{|c|c|c|}
\hline \multicolumn{3}{|c|}{$\begin{array}{l}\text { Table } 2 \text { | Summary characteristics of patient atter } \\
\text { Values are numbers (percentages) unless stated } \\
\text { otherwise }\end{array}$} \\
\hline All sites & Non-scribed & Scribed \\
\hline Total patients & 23838 & 5098 \\
\hline Male sext & $11816(50)$ & $2627(52)$ \\
\hline Age $(95 \% \mathrm{Cl})^{\star}$ & 43.1 (42.8 to 43.4$)$ & $41.2(40.9$ to 41.5$)$ \\
\hline \multicolumn{3}{|l|}{ Triaget: } \\
\hline Category 1 & $187(1)$ & $20(1)$ \\
\hline Category 2 & $4017(17)$ & $795(16)$ \\
\hline Category 3 & $10143(43)$ & $2138(42)$ \\
\hline Category 4 & $8063(34)$ & $1825(36)$ \\
\hline Category 5 & $1428(6)$ & $320(6)$ \\
\hline Admissions* & $7742(32)$ & $1481(29)$ \\
\hline
\end{tabular}

\section{Results}

Participant flow and recruitment

Figure 1 shows the flow of eligibility and recruitment. We staggered the trial periods at each site to allow for sufficient availability of scribes. Each data collection period started once sites were ready to accept scribes and was complete and ended once more than 100 scribe shifts were complete. Cabrini ran from October 2015 to September 2016, Dandenong from November 2016 to June 2017, Austin from February 2017 to October 2017, and Monash Paediatrics from July 2017 to January 2018. Bendigo, being rural with residential requirements for scribes, was completed in two phases to accommodate university semester breaks in winter (June to July 2017) and summer (November to December 2017).

\section{Baseline characteristics}

The 88 physicians (54 men) had ages ranging from 32 to 65 years. The 12 scribes (seven women) aged 19-28 years were half medical students and half pre-medical students. Table 2 summarises patients' demographics at each site during the respective trial periods, and appendix 2 describes them in detail. The scribe and non-scribe groups did not differ in major characteristics. Marked differences existed between sites in terms of patients' demographics.

\section{Outcomes and estimation}

Primary outcome

Scribes increased physicians' productivity from 1.13 (95\% confidence interval 1.11 to 1.17 ) to 1.31 (1.25 to
1.38) patients per hour per doctor, representing a $15.9 \%$ gain $(\mathrm{P}<0.001)$. Primary consultations increased from 0.83 (0.81 to 0.85 ) to 1.04 (0.98 to 1.11 ) patients per hour per doctor, representing a $25.6 \%$ gain $(\mathrm{P}<0.001)$. Table 3 shows the summary productivity changes, and the changes for individual sites are in appendix 3.

\section{Secondary outcomes}

Throughput measures showed no significant differences between door-to-doctor times. Median length of stay in emergency departments decreased from 192 (interquartile range 108-311) minutes to 173 (96-208) minutes for scribed shifts, or by 19 minutes $(\mathrm{P}<0.001)$. Table 3 shows the effect of the scribe on the ability of the physician to see new patients and manage secondary patients. Table 3 shows summary productivity and throughput data, and individual site date are in appendix 3.

Table 4 shows an analysis of the effect of the presence of scribes on regions of the emergency department, showing most benefit during senior doctor at triage shifts (gain of 0.53 or $24.9 \%$ primary patients per doctor per hour), some benefits in acute and paediatric regions, and no significant benefit during sub-acute, fast track, or observation ward shifts. When a scribe was allocated to the observation unit at Bendigo, the intern allocated to the observation unit for the shift was no longer needed, went to sub-acute/fast-track instead, and saw only new patients for the shift. The additional intern consultations were not counted in the study.

\section{Incidents when scribes were present}

Table 5 shows incidents recorded in the EMER database. Sixteen incidents involving scribes were recorded, with a reporting rate of one in every 300 consultations. The most common error category was patient identification (7/16; 44\%). A recurring scenario involved a patient incorrectly selected in the electronic medical record and then having an investigation ordered. In all scenarios, the scribe or doctor realised and prevented the investigation occurring. In $50 \%(8 / 16)$ of the incidents reported, the scribe was active in preventing a medical error.

\section{Cost-benefit analysis}

The results of the cost-benefit analysis are reported in appendix 1. Financial assumptions in generating this

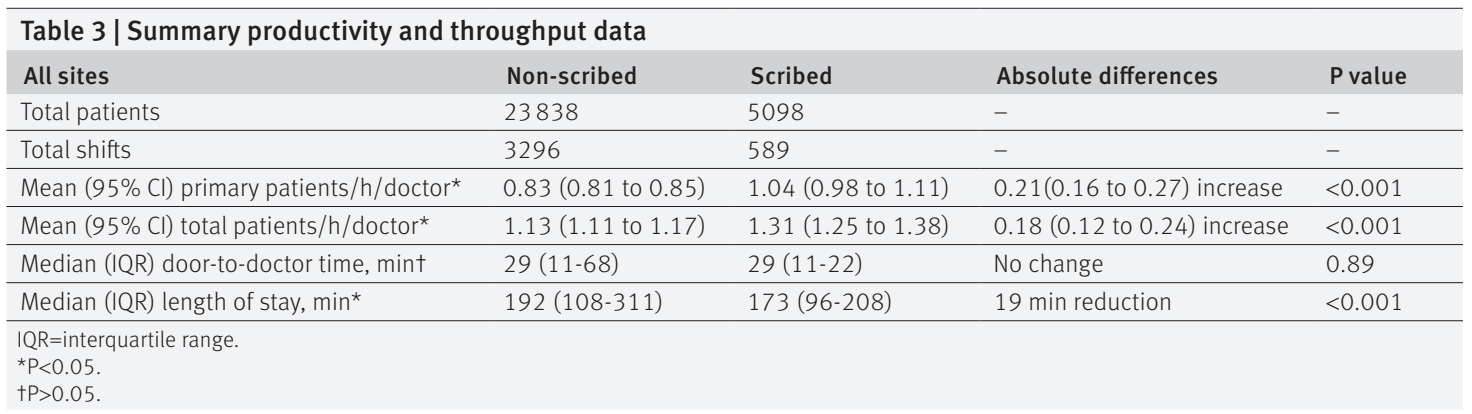




\begin{tabular}{|c|c|c|c|}
\hline Regions & Non-scribed & Scribed & Absolute change \\
\hline \multicolumn{4}{|c|}{ Senior doctor at triage (includes paediatric emergency department) } \\
\hline Total shifts & 155 & 55 & - \\
\hline Mean $(95 \% \mathrm{Cl}$ ) primary patients/h/doctor* & $2.13(1.96$ to 2.31$)$ & 2.67 (2.28 to 3.06$)$ & $0.53(0.16$ to 0.90$)$ increase \\
\hline Mean $(95 \% \mathrm{Cl})$ total patients/h/doctor* & $2.27(2.08$ to 2.46$)$ & $2.80(2.39$ to 3.21$)$ & 0.53 (0.14 to 0.93) increase \\
\hline \multicolumn{4}{|l|}{ Acute } \\
\hline Total shifts & 2172 & 322 & - \\
\hline Mean $(95 \% \mathrm{Cl}$ ) primary patients/h/doctor* & $0.71(0.70$ to 0.73$)$ & $0.82(0.78$ to 0.86$)$ & $0.10(0.06$ to 0.15$)$ increase \\
\hline Mean $(95 \% \mathrm{Cl}$ ) total patients/h/doctor* & 1.04 (1.01 to 1.06$)$ & $1.12(1.08$ to 1.17$)$ & 0.09 (0.03 to 0.15$)$ increase \\
\hline \multicolumn{4}{|l|}{ Sub-acute } \\
\hline Total shifts & 463 & 103 & - \\
\hline Mean $(95 \% \mathrm{Cl}$ ) primary patients/h/doctort & 1.05 (0.98 to 1.12$)$ & 1.03 (0.89 to 1.16$)$ & 0.02 (0.14 to 0.19$)$ reduction \\
\hline Mean $(95 \% \mathrm{Cl})$ total patients/h/doctort & $1.23(1.15$ to 1.31$)$ & 1.18 (1.02 to 1.33$)$ & $0.05(-0.14$ to 0.24$)$ reduction \\
\hline \multicolumn{4}{|l|}{ Paediatric } \\
\hline Total shifts & 506 & 109 & - \\
\hline Mean $(95 \% \mathrm{Cl})$ primary patients/h/doctor* & $0.75(0.72$ to 0.78$)$ & $0.92(0.82$ to 1.01$)$ & $0.17(0.09$ to 0.25$)$ increase \\
\hline Mean $(95 \% \mathrm{Cl})$ total patients/h/doctor* & $1.12(1.08$ to 1.16$)$ & 1.25 (1.16 to 1.35$)$ & 0.13 (0.04 to 0.22$)$ increase \\
\hline
\end{tabular}

analysis included that per patient revenue was assumed to be unchanged with the scribe present. Training the scribe cost US\$5015 per scribe, ${ }^{17}$ and scribes worked 1000 hours once trained, generating a cost per hour worked of US\$5 after completion of training. The scribes' hourly rate was US $\$ 20.51$ per hour. The physicians' hourly rate was US\$165, generating a saving of US $\$ 24.75$ per hour in physician time when the scribe was working (15\% gain in productivity). A 19 minute shorter length of stay generated a per patient saving in cubicle costs of $\$ 26.91$ per hour. The saving was US\$26.15 per scribed hour if the hospital paid for the scribe training and US\$31.15 per scribed hour if the scribe paid for the training.

\section{Discussion}

At most sites in our study, the presence of scribes was associated with productivity gains, with a greater increase for primary patients than secondary patients. Regarding patient flow, we saw no change in doorto-doctor time and a 19 minute reduction in length of stay in the emergency department when a scribe was present. When assessing productivity changes by emergency department region, more were gains achieved when the scribe worked with a physician at triage. Productivity gains also occurred in acute/ resuscitation bays and in paediatric areas. Subacute/fast track areas showed little to no productivity benefits from scribes. The number of reported adverse events with a scribe present was low, often related to identification of patients, and the presence of scribes at times worked as a protective factor in reducing medical error. ${ }^{31}$

\section{Strengths and limitations of study}

This is the first multicentre, randomised study to evaluate physicians' productivity associated with scribes. It evaluated the effect of scribes in multiple different types of emergency department, serving very different patient populations. The study was limited to one Australian state, and all the emergency department directors were supportive of scribes. Physicians were aware of the study's aims (introducing a potential Hawthorn effect) and were able to opt out, and these factors may have led to overestimation of the effect of scribes. The number of times a scribe was asked not to attend a sensitive consultation by a patient or physician was not recorded, but we know from other studies that this is very uncommon (less than 1\%). ${ }^{415} 16$ We did not measure physicians' unrecorded overtime, which means that we did not capture data on whether physicians stayed after shifts to complete documentation in either group. We had no run-in period for scribe-physician partnerships, and physicians were largely inexperienced in using scribes. These factors could have led to an underestimation of the effect of scribes. Blinded randomisation of the shifts represents a real working environment, with the challenges of creating rosters to suit all workers, but randomisation reduces the chance of a strong scribephysician working relationship and could reduce productivity. ${ }^{6}$ Blinding at analysis was not possible, as the same investigators did database cleaning, merging, and analyses. This study excluded junior doctors owing to the similarity between the wages of scribes and junior doctors (unlikely to achieve economic benefits), so we have no information on the efficacy of scribes with this group. Allocation of patients to physicians was not randomised, and physicians may have chosen different patients when working with or without scribes.

Ours is also the first study to document patient safety incidents associated with scribes, but self reporting probably led to underestimation of the likely harms. ${ }^{32}$ Voluntary reporting of patient safety incidents captures only a small portion of incidents that occur, and there was no reporting from the control shifts. Furthermore, participants in the study may have been more likely to report incidents in which they prevented a medical error.

Although a previous single site evaluation confirmed patients' satisfaction with scribes, this may not be representative of all patient groups. Future work 


\begin{tabular}{|c|c|c|}
\hline Incident & Incident summary & Error categories \\
\hline 1 & $\begin{array}{l}\text { Scribe booked follow-up appointment for patient. IT permissions for appointment booking allowed scribe data entry } \\
\text { (scribe believed appointment to be booked) but did not allow appointment to be actioned }\end{array}$ & Handover; investigation \\
\hline 2 & $\begin{array}{l}\text { Duplicate radiography requests ordered by physician; scribe identified that patient did not need second study and } \\
\text { cancelled it. Doctor multi-tasking }\end{array}$ & Investigation \\
\hline 3 & $\begin{array}{l}\text { Paediatric patient kicking expensive medical equipment off bed. Scribe removed equipment to avoid it being broken. } \\
\text { Rest of team focusing on other tasks at the time }\end{array}$ & Equipment \\
\hline 4 & $\begin{array}{l}\text { Physician consulting with patient while nebuliser running. Scribe could not hear most of consultation and documented it } \\
\text { incorrectly. Physician corrected documentation at editing/verification of scribe work stage }\end{array}$ & Documentation; medication \\
\hline 5 & $\begin{array}{l}\text { Scribe was threatened and almost assaulted by patient during consultation. No basic violence avoidance training in } \\
\text { scribe course. Did not realise that they could walk out of room if threatened }\end{array}$ & Violence \\
\hline 6 & $\begin{array}{l}\text { Scribe left patient name as "John Doe" in medical record rather than understanding that it should be edited out once } \\
\text { patient was identified. Physician did not identify error at verification stage. No process had been developed for scribe } \\
\text { or physician as to how to deal with time critical patients and need for patient's name to enable IT systems to function. } \\
\text { Scribe identified error later and corrected chart }\end{array}$ & Patient identification \\
\hline 7 & $\begin{array}{l}\text { Physician unable to see electronic triage notes at bedside. Young child had upper limb injury. Stressed mother showed } \\
\text { physician uninjured limb for examination and radiography. Scribe could see electronic triage in room and intervened, } \\
\text { cancelling incorrect radiography. They established that other limb was injured. Radiograph confirmed fracture }\end{array}$ & Treatment; investigation \\
\hline 8 & $\begin{array}{l}\text { Trauma patient evaluated by physician after paramedics had handed over to nurses. Patient had dementia and could } \\
\text { not recall events of day clearly. Nurse handover to physicians omitted details of trauma. Scribe read written ambulance } \\
\text { report (printed } 30 \text { min after physician consultation) and identified important features of trauma event that changed } \\
\text { management }\end{array}$ & Transfer; handover; documentation \\
\hline 9 & $\begin{array}{l}\text { While physician was charting drugs for patient by using pill packets brought from home, scribe collected another pa- } \\
\text { tient's drugs and placed them in same pile. These were incorrectly recorded in original patient's chart. Error was realised } \\
\text { later when second drug chart was being written, and error was corrected by physician }\end{array}$ & Patient identification; medication \\
\hline 10 & $\begin{array}{l}\text { Scribe assigned physician to patient electronically. Physician did not realise this. Scribe did not prompt physician. After } \\
\text { prolonged patient wait for physician, error was identified }\end{array}$ & $\begin{array}{l}\text { Patient identification; prolonged } \\
\text { length of stay; documentation }\end{array}$ \\
\hline 11 & $\begin{array}{l}\text { Specialist attended ED to consult on patient. Specialist read results of wrong patient and made management plans based } \\
\text { on this interpretation. Scribe read plan, realised error, and advised physician. Error corrected }\end{array}$ & Patient identification; investigation \\
\hline 12 & $\begin{array}{l}\text { CT ordered for patient. Patient location changed in ED after order. Porter took wrong patient from original location to CT } \\
\text { without complete identity checks. Scribe saw this happening, intervened, and brought wrong patient back from radiology } \\
\text { before scan }\end{array}$ & Patient identification; investigation \\
\hline 13 & $\begin{array}{l}\text { Physician ordered CT on EMR while wrong patient chart was opened. Scribe observed this, intervened, and corrected } \\
\text { error }\end{array}$ & Patient identification; investigation \\
\hline 14 & $\begin{array}{l}\text { Scribe watched patient with a multi-resistant organism infection be discharged from ED. Just before new patient occupied } \\
\text { cubicle, scribe intervened to ask why room had not been cleaned to decontaminate for this organism. Room cleaned } \\
\text { before new patient occupation }\end{array}$ & Bed allocation \\
\hline 15 & $\begin{array}{l}\text { Scribe and doctor underestimated severity of patient's presentation. Nurse correctly identified deterioration and ar- } \\
\text { ranged for patient to be admitted }\end{array}$ & Failure to recognise severity \\
\hline 16 & $\begin{array}{l}\text { Scribe ordered radiography for wrong patient. Scribe identified error and intervened. Scribes are not licensed to order } \\
\text { imaging, and this represents scope creep for role }\end{array}$ & Patient identification; investigation \\
\hline
\end{tabular}

would benefit from involvement of patients from the start of the study, so the values and preferences are representative and generated by patients and members of the public.

\section{Comparison with other studies}

Heaton et al's 2016 meta-analysis of four productivity studies ${ }^{1153334}$ showed increases of 0.17 (95\% confidence interval 0.02 to 0.32 ) patients per hour, ${ }^{24}$ which is of a similar magnitude to the findings in our study. However, the study methods were limited, all were non-randomised, and half were retrospective. Since then, Heaton et al have published a single centre prospective block allocation study, ${ }^{11}$ finding no significant change in physicians' productivity in adult or paediatric emergency department regions, which differs from our overall analysis but not from one of our individual sites. Our study found that productivity changes varied according to the role of the physician, which is contrary to the findings of a previous small study. ${ }^{16}$

\section{Conclusions and policy implications}

For clinicians and policy makers, our study shows that scribes can increase productivity in Australian emergency departments. Our example cost-benefit analysis (appendix 1) shows a cost saving to the hospital per scribed hour of US\$26.15 when the hospital absorbs the cost of training. This analysis will vary from site to site, depending on the hourly costs of physicians and scribes (including training) and cubicle minute costs. Other factors to consider will be revenue change per patient and changes in productivity and throughput. All sites should pilot their programme and do financial modelling to ensure that they are achieving benefits. How to implement a scribe programme outside the US has been described in detail. ${ }^{18}$ Physicians vary in their ability to use scribes effectively, ${ }^{16}$ and this should also be kept in mind when writing rosters.

Our study has also shown a decrease in length of stay at all sites. This decreased length of stay should be considered in any economic analysis. The time savings allow for additional patients to be seen, so overall costs per patient may decrease. This time reduction will also improve the flow of and access for patient and contribute to achieving the various time based targets most emergency departments are required to achieve. Hospitals finding staffing of emergency departments 
challenging (such as some rural centres) may wish to determine how junior doctors perform with scribes. Training scribe and physician teams in correct patient identification techniques may be helpful in reducing patient safety events. Given the strong preference of physicians for working with a scribe, ${ }^{6}$ no effect on the patient experience, ${ }^{4}$ minimal risk, and the productivity and throughput gains outlined, emergency department and hospital administrators should strongly consider the potential local utility of scribes in their workforce and financial planning.

Future work should include testing scribes in other settings and countries and involve patients in the research team. Specific studies should be done to identify the harms and benefits of scribes in terms of quality and risk. The impact of varying electronic medical records and how this affects the utility of scribes has not been tested.

In conclusion, scribes led to productivity gains that were greatest in primary patient consultations. Sites and emergency department regions varied in the magnitude of the gains. Reductions were seen in length of stay but not in door-to-doctor times. Financial analysis based on gains in productivity and throughput supports implementation of scribes.

\section{AUTHOR AFFILIATIONS}

${ }^{1}$ Emergency Department, Cabrini Hospital, Malvern, VIC 3144, Australia

${ }^{2}$ Department of Epidemiology and Preventive Medicine, Monash University, Melbourne, VIC, Australia

${ }^{3}$ Australian National University, Canberra, ACT, Australia

${ }^{4}$ Emergency Department, Monash Health, Dandenong, Melbourne, VIC, Australia

${ }^{5}$ Emergency Department, Austin Health, Heidelberg, VIC, Australia

${ }^{6}$ University of Melbourne, Melbourne, VIC, Australia

${ }^{7}$ Emergency Department, Bendigo Health, Bendigo, VIC, Australia

${ }^{8}$ Emergency Department, Melbourne Health, Parkville, VIC, Australia

${ }^{9}$ Emergency Department, Prince Charles Hospital, Chermside, QLD, Australia

${ }^{10}$ Emergency Department, St Andrews War Memorial Hospital, Brisbane, QLD, Australia

${ }^{11}$ Emergency Department, Royal Victorian Eye and Ear Hospital, East Melbourne, VIC, Australia

${ }^{12}$ School of Public Health and Preventive Medicine, Monash University, Melbourne, VIC, Australia

${ }^{13}$ Emergency Medicine, Austin Health, Heidelberg, VIC, Australia

${ }^{14}$ Biostatistics, Cabrini Institute, Malvern, VIC, Australia

We thank the emergency department teams at each site for supporting the research and particularly the participating emergency physicians and scribes. We thank the patients, whose data made this study possible. We also thank the following for their assistance in supporting and developing the research and scribe programmes: Cabrini Health and Institute, Andis Graudins, Robert Meek, Neil Goldie, Simon Judkins, and Kathryn Wilson (ethics application).

Prospective registration 10 June 2015, ACTRN12615000607572: A pilot study of the relationship between Australian trained emergency department scribes and emergency physicians' productivity. In 2015 the study group received enough philanthropic support to start training and evaluating the effect of Australian scribes, rather than relying on American scribes living in Melbourne for brief periods. This trial registration describes evaluation of the productivity of physicians working with and without scribes at our first site (Cabrini). These site data were combined with data from other sites in this paper. We reported some outcomes in other publications (number of clinical shifts needed to train a scribe, cost of training a scribe, productivity of physicians while working with trainee scribes ${ }^{17}{ }^{18}$ ). When scribes achieved competency (no longer trainees), productivity and throughput data were collected for this study. We did not measure or report data on the following secondary outcomes: staff and patient satisfaction (separate studies were done simultaneously and registered and reported elsewhere ${ }^{46}$ ); complaints (none were received and we report possible harms, collected via the Emergency Medicine Events Registry, in this manuscript instead); periods of time spent on ambulance bypass/diversion (not measured). Completion of this section of the study and demonstration that we had the capability to deliver the project allowed us to seek and achieve funding for an additional four study sites.

Prospective registration 12 May 2016, ACTRN12616000618459: A prospective, multicentre cohort study, evaluating emergency doctor productivity with medical scribe assistance. On 16 September 2016 we changed the sample size required in the registry in response to two updated data points. We determined, from newer datasets during scribe training, that medical productivity (without scribes) had decreased at Cabrini since our first sample size estimate, and we determined the cost of training scribes in Australia, which was previously unknown. This required a doubling of our sample size at each site from 50 to 100 scribed shifts. In this evaluation, we report the primary outcome (patients per hour per doctor) and secondary outcomes 2 and 3 (door-to-doctor and door-to-discharge/emergency department length of stay times). We evaluated the quality of scribes notes and report the evaluation elsewhere. ${ }^{9}$ We did not measure and do not report the following secondary outcomes (with and without scribes): door-to-medical triage times; stress levels of physicians; per patient revenues; comparison of dictation to scribe (patients per hour per doctor). We received enough funding to do the five site evaluation of productivity, but not enough to evaluate the remaining outcomes. This decision was made before data collection was done. We changed the trial registry outcomes on 13 June 2018 to remove the outcomes we did not evaluate.

Contributors: KW and MBM obtained funding. KW and WD obtained ethics approval. KW, MS, DT, DL, WD, MBM, KH, and CC developed the methods for the study. KW, WD, RR, AW, GOC, MP, and DB were responsible for site implementation and data collection. WD was responsible for data cleaning. KW, WD, MS, KH, CC, and MBM were involved in data analysis. KW, WD, MBM, MS, KH, CC, DT, and DL wrote the manuscript, and all authors revised it. All authors had access to all of the data (including statistical reports and tables) and can take full responsibility for the integrity of the data and the accuracy of the data analysis. The corresponding author attests that all listed authors meet authorship criteria and that no others meeting the criteria have been omitted. KW is the guarantor.

Funding: The study was funded by Equity Trustees, the Phyllis Connor Memorial Fund, Cabrini Foundation, and Cabrini and supported by the Cabrini Institute. Funders had no role in study design or protocol, results, or write-up or manuscript submission decisions other than to provide funding. The researchers were independent of the funders. Competing interests: All authors have completed the ICMJE uniform disclosure form at www.icjme.org/coi_disclosure.pdf (available on request from the corresponding author) and declare: support from the Cabrini Institute for the submitted work; KW is the director of the Cabrini scribe programme; WD is a head scribe and research assistant; the Phyllis Connor Memorial Fund has supported KW and WD to attend conferences to present scribe data; no other relationships or activities that could appear to have influenced the submitted work.

Ethical approval: Human research ethics committee (Monash, Cabrini, Austin, Bendigo Health) approval numbers Monash HREC 16392L, Cabrini HREC 06-27-07-15. All scribes and physicians gave consent before participation in the study.

Data sharing: Medical researchers can obtain de-identified data by contacting the corresponding author.

Transparency: The lead author affirms that the manuscript is an honest, accurate, and transparent account of the study being reported; that no important aspects of the study have been omitted; and that any discrepancies from the study as planned (and, if relevant, registered) have been explained.

This is an Open Access article distributed in accordance with the Creative Commons Attribution Non Commercial (CC BY-NC 4.0) license, which permits others to distribute, remix, adapt, build upon this work non-commercially, and license their derivative works on different terms, provided the original work is properly cited and the use is noncommercial. See: http://creativecommons.org/licenses/by-nc/4.0/.

1 Arya R, Salovich DM, Ohman-Strickland P, Merlin MA. Impact of scribes on performance indicators in the emergency department. 
Acad Emerg Med 2010;17:490-4. doi:10.1111/j.15532712.2010.00718x

2 Yan C, Rose S, Rothberg MB, Mercer MB, Goodman K, Misra-Hebert AD. Physician, Scribe, and Patient Perspectives on Clinical Scribes in Primary Care. J Gen Intern Med 2016;31:990-5. doi:10.1007/ s11606-016-3719-x

3 Bastani A, Shaqiri B, Palomba K, Bananno D, Anderson W. An ED scribe program is able to improve throughput time and patient satisfaction. Am J Emerg Med 2014;32:399-402. doi:10.1016/j. ajem.2013.03.040

4 Dunlop W, Hegarty L, Staples M, Levinson M, Ben-Meir M, Walker K. Medical scribes have no impact on the patient experience of an emergency department. Emerg Med Australas 2018;30:61-6. 10.1111/1742-6723.12818

5 Ou E, Mulcare M, Clark S, Sharma R. Implementation of Scribes in an Academic Emergency Department: The Resident Perspective. / Grad Med Educ 2017;9:518-22. doi:10.4300/JGME-D-16-00807.1

6 Cowan TL, Dunlop WA, Ben-Meir M, et al. Emergency consultants value medical scribes and most prefer to work with them, a few would rather not: a qualitative Australian study. Emerg Med J 2018;35:12-7. doi:10.1136/emermed-2017-206637

7 Hess JJ, Wallenstein J, Ackerman JD, et al. Scribe Impacts on Provider Experience, Operations, and Teaching in an Academic Emergency Medicine Practice. West J Emerg Med 2015;16:602-10. doi:10.5811/westjem.2015.6.25432

8 Misra-Hebert AD, Amah L, Rabovsky A, et al. Medical scribes: How do their notes stack up?] Fam Pract 2016;65:155-9.

9 Walker KJ, Wang A, Dunlop W, Rodda H, Ben-Meir M, Staples M. The 9-Item Physician Documentation Quality Instrument (PDQI-9) score is not useful in evaluating EMR (scribe) note quality in Emergency Medicine. Appl Clin Inform 2017;8:981-93. doi:10.4338/ $\mathrm{ACl} 2017050080$

10 Bastani A, Shaqiri B, Palomba K, Bananno D, Anderson W. An ED scribe program is able to improve throughput time and patient satisfaction. Am J Emerg Med 2014;32:399-402. doi:10.1016/j. ajem.2013.03.040

11 Heaton HA, Nestler DM, Jones DD, et al. Impact of scribes on patient throughput in adult and pediatric academic EDs. Am J Emerg Med 2016;34:1982-5. doi:10.1016/j.ajem.2016.07.011

12 Heaton HA, Nestler DM, Jones DD, et al. Impact of Scribes on Billed Relative Value Units in an Academic Emergency Department. J Emerg Med 2017;52:370-6. doi:10.1016/j.jemermed.2016.11.017

13 Heaton HA, Nestler DM, Lohse CM, Sadosty AT. Impact of scribes on emergency department patient throughput one year after implementation. Am J Emerg Med 2017;35:311-4. doi:10.1016/j. ajem.2016.11.017

14 Shuaib W, Hilmi J, Caballero J, et al. Impact of a scribe program on patient throughput, physician productivity, and patient satisfaction in a community-based emergency department. Health Informatics J 2017;1460458217704255.

15 Walker K, Ben-Meir M, O’Mullane P, Phillips D, Staples M. Scribes in an Australian private emergency department: A description of physician productivity. Emerg Med Australas 2014;26:543-8. doi:10.1111/1742-6723.12314

16 Walker KJ, Ben-Meir M, Phillips D, Staples M. Medical scribes in emergency medicine produce financially significant productivity gains for some, but not all emergency physicians. Emerg Med Australas 2016;28:262-7. doi:10.1111/1742-6723.12562

17 Walker KJ, Dunlop W, Liew D, et al. An economic evaluation of the costs of training a medical scribe to work in Emergency Medicine. Emerg Med / 2016;33:865-9. doi:10.1136/ emermed-2016-205934
18 Walker K, Johnson M, Dunlop W, et al. Feasibility evaluation of a pilot scribe-training program in an Australian emergency department. Aust Health Rev 2018;42:210-7. doi:10.1071/AH16188

19 Bank AJ, Gage RM. Annual impact of scribes on physician productivity and revenue in a cardiology clinic. Clinicoecon Outcomes Res 2015:7:489-95 doi:10.2147/CEOR.S89329

20 Bank AJ, Obetz C, Konrardy A, et al. Impact of scribes on patient interaction, productivity, and revenue in a cardiology clinic: a prospective study. Clinicoecon Outcomes Res 2013;5:399-406. doi:10.2147/CEOR.S49010

21 Koshy S, Feustel PJ, Hong M, Kogan BA. Scribes in an ambulatory urology practice: patient and physician satisfaction. J Urol 2010;184:258-62. doi:10.1016/i.juro.2010.03.040

22 Norris B, Harris T, Stringer S. Effective use of physician extenders in an outpatient otolaryngology setting. Laryngoscope 2011;121:231721. doi:10.1002/lary.22192

23 Gidwani R, Nguyen C, Kofoed A, et al. Impact of Scribes on Physician Satisfaction, Patient Satisfaction, and Charting Efficiency: A Randomized Controlled Trial. Ann Fam Med 2017;15:427-33. doi:10.1370/afm.2122

24 Heaton HA, Castaneda-Guarderas A, Trotter ER, Erwin PJ, Bellolio MF. Effect of scribes on patient throughput, revenue, and patient and provider satisfaction: a systematic review and meta-analysis. Am Emerg Med 2016;34:2018-28. doi:10.1016/j.ajem.2016.07.056

25 Shultz CG, Holmstrom HL. The use of medical scribes in health care settings: a systematic review and future directions. I Am Board Fam Med 2015;28:371-81. doi:10.3122/jabfm.2015.03.140224

26 Abdulwahid MA, Booth A, Kuczawski M, Mason SM. The impact of senior doctor assessment at triage on emergency department performance measures: systematic review and meta-analysis of comparative studies. Emerg Med / 2016;33:504-13. doi:10.1136/ emermed-2014-204388

27 Kingsley K, Thompson A. Medical Scribe Training Systems. 2018. https://www.medicalscribetraining.net.

28 Thompson A, Kingsley K. The Ultimate Medical Scribe Handbook: Emergency Department Edition. Createspace Independent Pub, 2014.

29 Kee R, Knott JC, Dreyfus S, Lederman R, Milton S, Joe K. One hundred tasks an hour: an observational study of emergency department consultant activities. Emerg Med Australas 2012;24:294-302. doi:10.1111/j.1742-6723.2012.01540.x

30 Hansen K, Schultz T, Crock C, Deakin A, Runciman W, Gosbell A. The Emergency Medicine Events Register: An analysis of the first 150 incidents entered into a novel, online incident reporting registry. Emerg Med Australas 2016;28:544-50. doi:10.1111/17426723.12620

31 Patterson ES, Woods DD, Cook RI, Render ML. Collaborative crosschecking to enhance resilience. Cogn Technol Work 2007;9:155-62. doi:10.1007/s10111-006-0054-8 .

32 Silas R, Tibballs J. Adverse events and comparison of systematic and voluntary reporting from a paediatric intensive care unit. Qual Saf Health Care 2010;19:568-71.

33 Chen PW, Dowling S, Abernethy R, Innes G. Assessment of scribes in Calgary emergency departments. Can J Emerg Med 2012;14:S29.

34 Marshall JS, Verdick CM, Tanaka MS, et al. 296 Implementation of Medical Scribes in an Academic Emergency Department: Effect on Emergency Department Throughput, Clinical Productivity, and Emergency Physician Professional Fees. Ann Emerg Med 2012;60(Supplement):S105. doi:10.1016/j. annemergmed.2012.06.274

\section{Appendix 1-3}

